\title{
Exploration of Students' Problem-Solving Skills in Physics-Based on Expert and Novice Categories
}

\author{
Nehru $^{1}$, Wawan Kurniawan ${ }^{2}$, Cicyn Riantoni ${ }^{3}$ \\ \{nehru@unja.ac.id ${ }^{1}$, kurniawan_wawan@unja.ac.id², cicynriantoni12@gmail.com³ \\ Physics Education Department, Faculty of Education, Universitas Jambi, J1 Lintas Jambi-Muara \\ Bulian Km 15, Muaro Jambi, Jambi, Indonesia ${ }^{1,2,3}$
}

\begin{abstract}
In agreement with conceptual understanding, identifying problem-solving skills is an important topic in physics. The purpose of this research was to explore students' problem-solving skills based on expert and novice categories. The research used a mixedmethod approach with an explanatory model with 34 prospective physics teachers at Jambi University, Indonesia. The data was obtained by using open-ended questions. Data were collected using tests and interviews. Data analysis was done by using the rubric for physics problem-solving skills. Problem-solving skills were classified into expert and novice. The research showed that most students have problem-solving skills by novice categories. The cause is the weak application of concepts in the problem-solving process. The research concludes application of the concept in the process of problem-solving not well understood by most students be the reason most students have categories novice ability in problemsolving.
\end{abstract}

Keywords: Problem-Solving Skills, Expert, Novice

\section{Introduction}

The main topics of research in the field of University physics education are conceptual understanding, problem-solving, curriculum, and teaching, assessment, cognitive psychology, attitudes and beliefs about teaching and learning [1]. Each topic has a theoretical description of important parts that must be studied continuously. This is intended to find strategies so that physics is easy to discuss.

One important topic of the six topics highlighted is problem-solving [13]. Problem-solving is always highlighted in physics education because of the key components of physics learning [1],[3]. Teachers in the physics field usulally pay great attention to the way students solve problems because in the process of solving problems students can understand the concept of understanding and one strategy to determine student achievement [2],[3],[4],[12]. Problemsolving is generally used by physics teachers as a mechanism for teaching and evaluating the material being studied [3],[4].

In the last decades, five frequently asked questions related to problem-solving include, (1) solving expert and novice problems, (2) how examples of problem-solving and discussion, (3) representations used in problem-solving, (4) ability mathematics in problem-solving, (5) evaluating the effectiveness of strategies in problem-solving [1]. Of these five topics, mathematical abilities and representations [3] used in problem-solving are most often discussed. That is because research on representation in problem-solving has a long history [11] and many 
assumptions that assume students' difficulties in problem-solving are due to the lack of mathematical skills. But an explanation of how physics knowledge is structured in memory is still little discussed, especially concerning the memory structure of an expert and novice.

Some expert and novice research in problem-solving only focus on distinguishing procedures between expert and novice. very little research has focused on the memory structure of students in solving problems. This article aims to discuss how physical knowledge is structured in memory adjusted to the expert and novice categories.

\section{Method}

This research is mixed-method research with explanatory model design [5]. The research subjects were students of Physics Education at Jambi University who were studying electrical material. The number of respondents was 35 students. Respondents were selected by purposive sampling technique. The research design used in this study is shown in Figure 1.

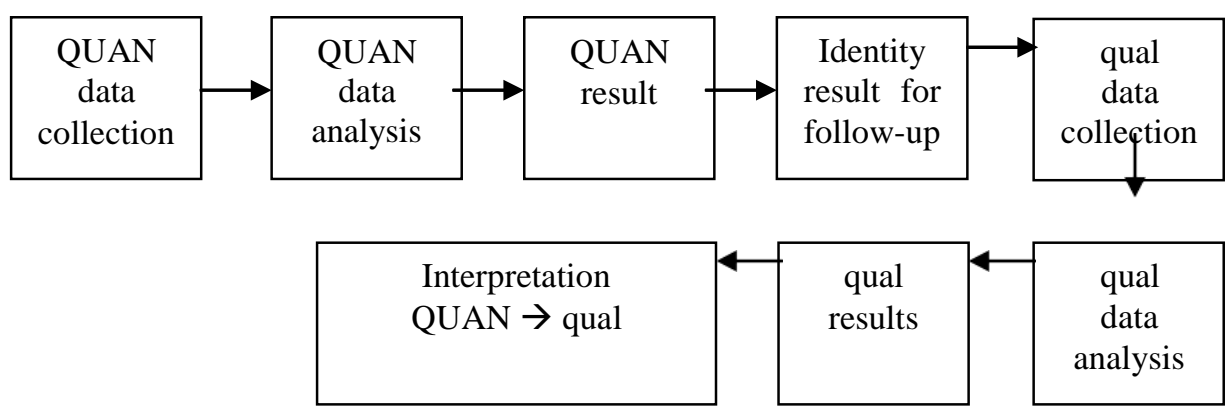

Fig. 1. Explanatory design: Follow-up Explanation model (QUAN emphasized).

Data collection is done by tests and interviews. The test instruments used were two reasonable multiple-choice questions developed by researchers, which focused on dynamic electric material. The choice of dynamic electric material is based on solving the problem of this material requires the ability to connect between concepts is good, although the concepts in dynamic electric material are very simple. The instrument has been reviewed by 2 lecturers of UNJA Physics education and has gone through empirical tests, the results of which have concluded that the instrument has high validity and reliability. The interview was conducted in a structured manner based on the initial design that was prepared on the results of student tests. The interview aims to explore deeper the students' problem-solving abilities. Meanwhile, data analysis of test and interview results to explore the ability of students in the expert and novice categories is based on the characteristics of experts and novices that have been compiled by researchers from several theories expressed by several experts. The characteristics of experts and novices are shown in Table 1. The process of data analysis was carried out in 2 steps, namely (1) the data was analyzed based on test results using 3 reasoned multiple-choice questions, (2) the test results were further corroborated by the results of interviews, interview data analysis was carried out with reduce and then coded to support the test results based on the characteristics of experts and novices. 
Table 1. Characteristics of expert and novice.

\begin{tabular}{|c|c|}
\hline Criteria & Characteristics \\
\hline Expert & 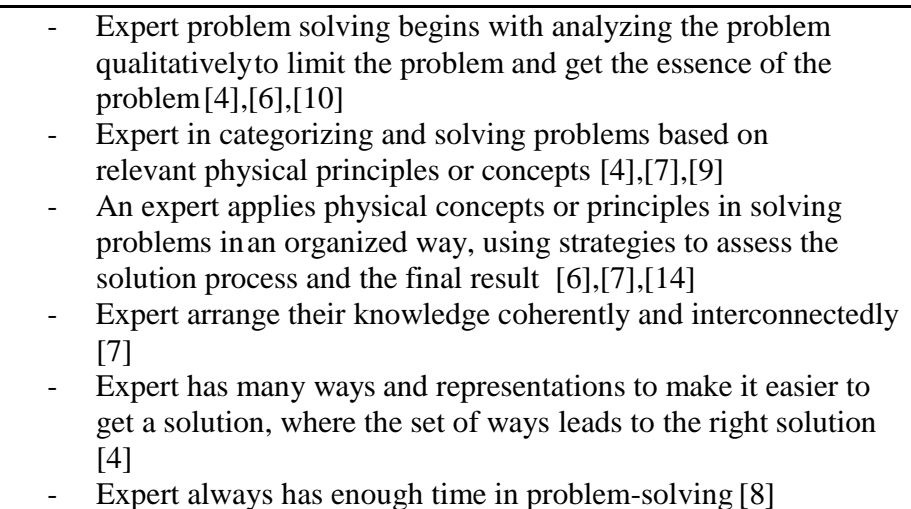 \\
\hline Novice & $\begin{array}{l}\text { Novice solves the problem of focusing on quantitative } \\
\text { values and tries to match them with mathematical } \\
\text { procedures or formulas [4],[6],[7] } \\
\text { - Novice may do qualitative analysis, but it is not perfect and } \\
\text { does not do it directly [4],[6] } \\
\text { - Novice solves problems not based on basic principles or } \\
\text { concepts of physics but based on variables and manipulation of } \\
\text { equations [7] } \\
\text { - Novice does not have organized knowledge to solve problems, } \\
\text { they are solving problems randomly and have little conceptual } \\
\text { meaning [10] } \\
\text { Novice has lost, weak or unrelated knowledge is very fast } \\
\text { getting into trouble and slow in finding other alternatives in } \\
\text { solving problems [8],[10] } \\
\text { Novice sees the problem in pieces [10] } \\
\text { - Novice has weakness in conceptual, mathematical skills, and the } \\
\text { ability to transfer knowledge [7] }\end{array}$ \\
\hline
\end{tabular}

\section{Result and Discussion}

Student's problem-solving skills are not only seen from the improvement of problemsolving skills after learning is given, but also students' steps in the problem-solving process. Exploring student steps in problem-solving is based on expert and novice criteria. This is because developing the ability to become an expert in the problem-solving process is the main goal of most physics learning [15]. Statistical data on students' problem-solving abilities are presented in Figure 2. 


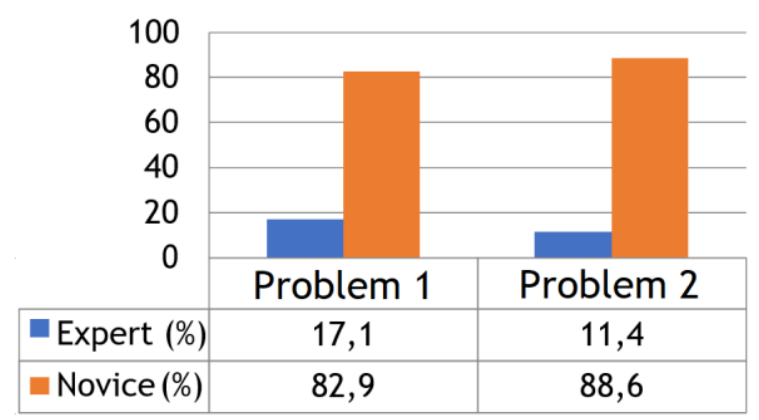

Fig. 2. Percentage of students' ability in solving problems based on the Expert and Novice categories.

The percentage of test results and interviews for each item in Figure 2 shows that most students are categorized as novices in the problem-solving process. Students who are categorized as novices in problem-solving characterize have weaknesses in conceptual understanding, mathematics, and knowledge transfer skills and this is an obstacle for students in solving problems [7]. To understand the reason that there are still very few students in the expert category in solving physics problems, the following are presented various characteristics of students in solving physics problems, especially dynamic electric material.

\subsection{Students' Problem Solving Skill For Number 1}

The first problem is given in the context of changing the magnitude of the potential difference around an obstacle that is arranged in a series and parallel mixture with a switch in one of the branches being closed and opened. The results of the analysis found $17.1 \%$ of students were categorized as experts in solving the problem and $82.9 \%$ were still in the novice category. A summary of the student problem-solving process based on the results of the analysis is presented in Table 2.

Table 2. Characteristics of Problem-Solving Process Problem Number 1 Based on Expert and Novice Categories.

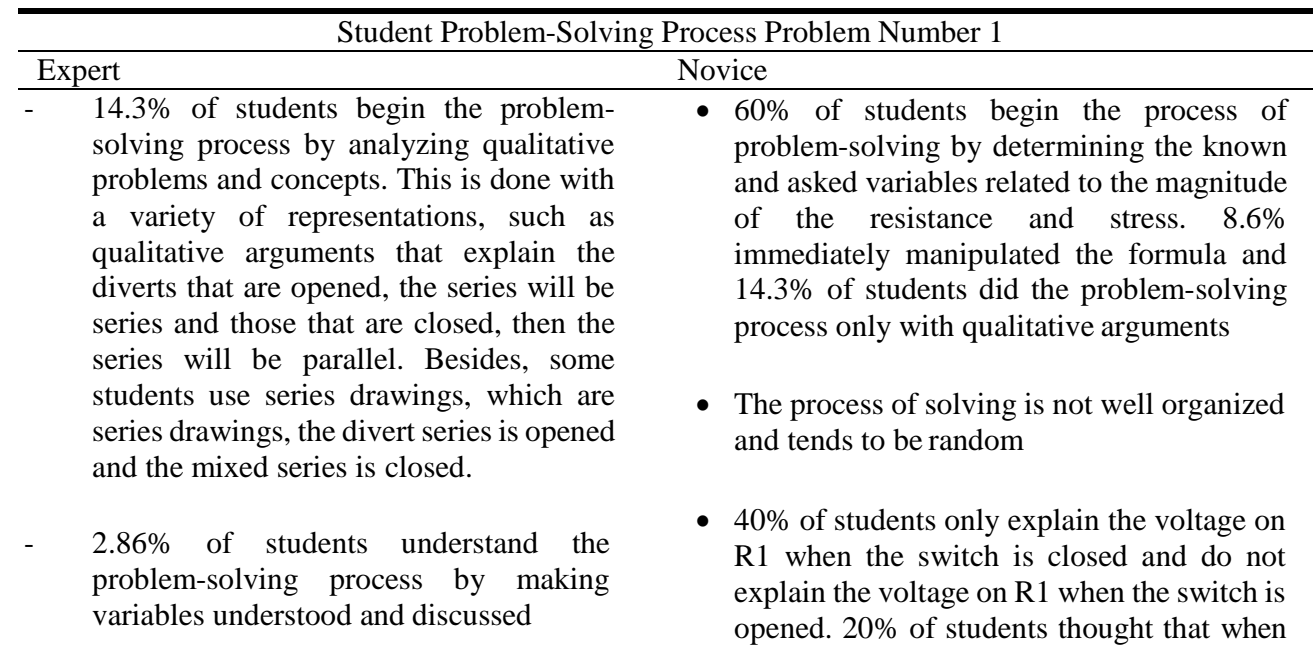




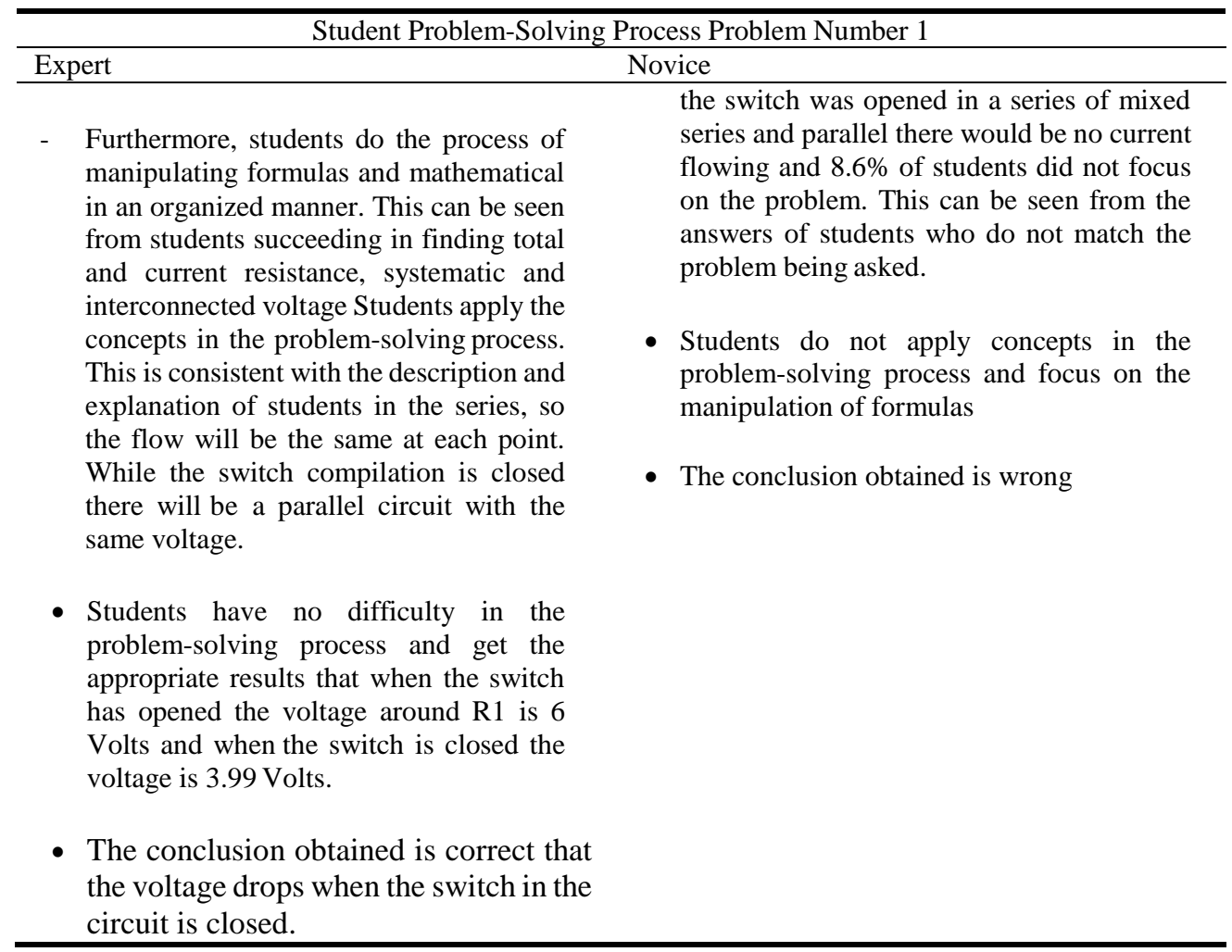

Based on Table 2, illustrates that students do not apply a scientific approach to the problemsolving process. The proof can be seen from the absence of applied concepts, the problemsolving process that is not well organized and tends to be random, and always starts by determining the variables. Yet according to the theory of Walsh, Howard, and Bowe, the characteristics of an expert in solving problems are to use a scientific approach. The steps of a scientific approach include, (1) initiating the problem-solving process by analyzing the problem qualitatively, (2) systematically planning and finding solutions, (3) applying the concepts in each problem-solving process, and (4) always evaluating solutions has been given [10].

\subsection{Students' Problem Solving Skill for Number 2}

The second problem is given in the context of applying the concepts of current, voltage and electric power in a series of mixed series and parallel in two circumstances, namely the switch is closed and opened. The analysis results obtained $11.4 \%$ of students who fall into the expert category in solving the problem and $88.6 \%$ are still in the novice category. A summary of the steps to solving students' problems in problem number 2 is presented in Table 3. 
Table 3. Characteristics of Problem-Solving Process Problem Number 2 Based on Expert and Novice Categories.

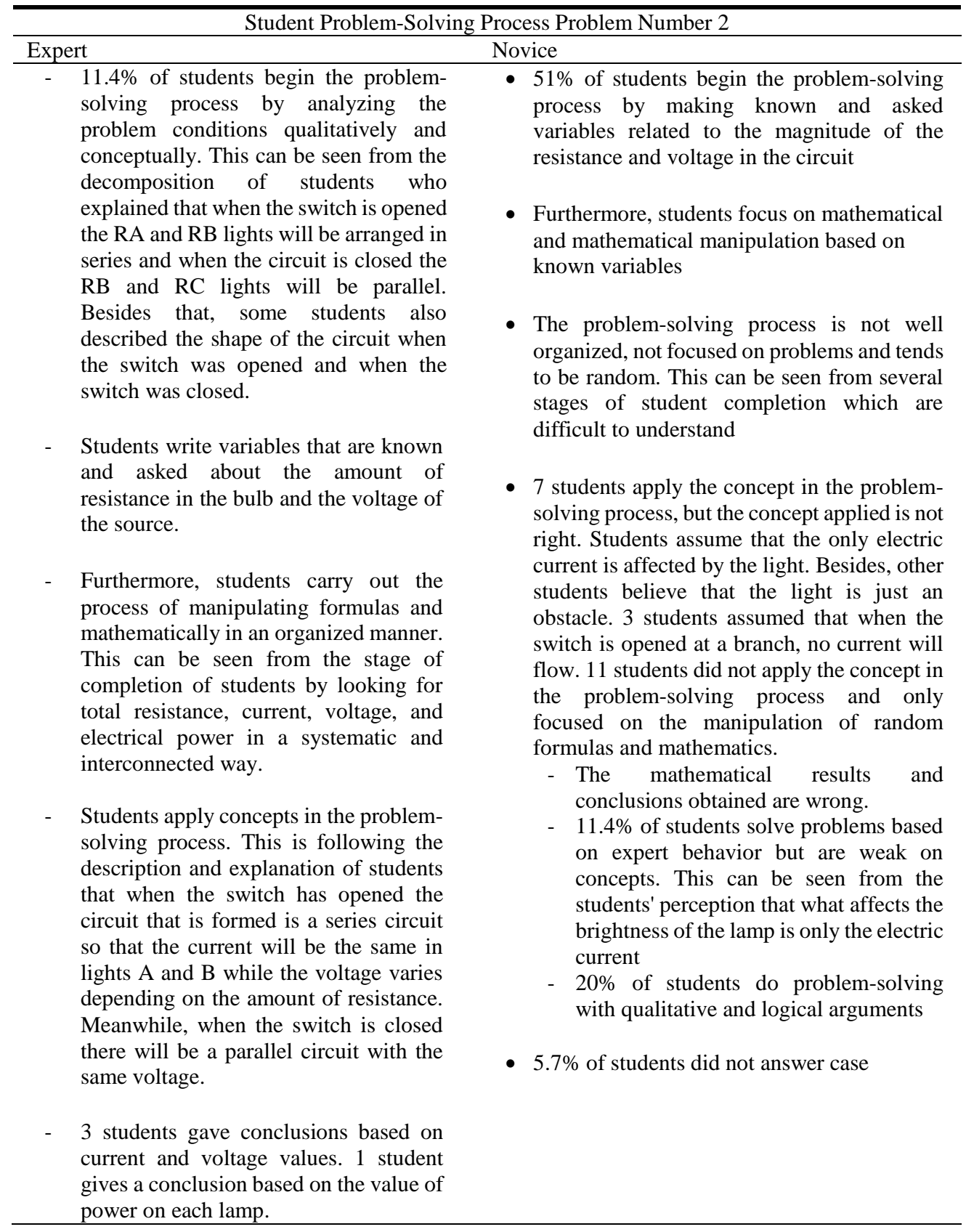

Based on Table 3 shows that students in problem-solving tend to start the problem-solving process by making variables known and asked. These characteristics indicate that students are 
still categorized as novices in problem-solving. This is consistent with previous research, which states that a novice in the problem-solving process focuses on quantitative values and tries to match them with mathematical procedures [4][6]. Novice tends to solve the problem by directly manipulating the equation [7]. The biggest weakness of a novice is that it does not include the correct concepts of physics in problem-solving. Novice solves problems based on little understanding and does not apply relevant concepts [8],[9].

\section{Conclusion}

Based on the results and discussion, it can be concluded that the category of students in the problem-solving process is still categorized as a novice. This is because most students do the problem-solving process based on the variables determined at the beginning, do not use concepts, focus on formula manipulation and each step is not well organized. To further this research, it is advisable to investigate the different steps of problem-solving or structured physics knowledge in the memory of a lecturer and student.

Acknowledgments. The authors would like to thank the LPPM Jambi University for funding the project and for the Department of Physics Education to their inspiring contributions.

\section{References}

[1] Doctor, J. L., Mestre, J. P.: Synthesis of discipline-based education research in physics. Physics Review Special Topics- Physics Education Research (2014)

[2] Ceberio, M., Almudi, J. S., Franco, A.: Design and application of interactive simulations in problem solving in university-level physics education. Journal Science Education and Technology (2016)

[3] Ibrohim, B., Rabello, N. S.: Representational task format and problem-solving strategies in kinematics and work. Physics Review Special Topics- Physics Education Research (2012)

[4] Docktor, J. L., Dornfeld, J., Frodermann, E., Heller, K., Hsu, L., Jackson, K. A., Mason, A., Qing X. R., Yang, J.: Assessing student written problem solutions: A problem- solving rubric with application to introductory physics. Physics Review Special Topics- Physics Education Research (2016)

[5] Creswell, J., Clark, V. P.: Designing and conducting mix methods research. Sage Publication, USA (2007)

[6] Ryan, Q.: Computer problem-solving coaches for introductory physics: Design and usability studies. Physics Review Special Topics- Physics Education Research (2016)

[7] Hull, M. M., Kuo, E., Gupta, A., Elby, A.: Problem-solving rubrics revisited: Attending to the blending of informal conceptual and formal mathematical reasoning. Physics Review Special TopicsPhysics Education Research (2013)

[8] Yureshalmi, E., Cohen, E., Heller, K., Heller, P., Henderson, C.: Instructors reasons for choosing problem features in a calculus-based introducory physics course. Physics Review Special TopicsPhysics Education Research (2010)

[9] Rosengrant, D., Heuvelen, A., Etkina, E.: Do students use and understand free-body diagrams? Physics Review Special Topics- Physics Education Research (2009)

[10] Walsh, L., Howard, R., Bowe, B.: Phenomenographic study of students' problem-solving approaches in physics. Physics Review Special Topics- Physics Education Research (2007) 
[11] Kohl, P.B., Rosengrant, D., Finkeilstein, N.D.: Strongly and Weakly Directed Approach to Teaching Multiple Representation Use in Physics. Physics Review Special Topics- Physics Education Research, Vol 3, No 010108 (2007)

[12] Adams,W.K.: Student Engagement And Learning With Phet Interactive Simulations. US: Department of Physics University of Colorado (2010)

[13] Leak, A.E., Rothwell, S.L., Olivera, J., \& Zwickl, B.: Examining Problem Solving in PhysicsIntensive Ph.D research. Physics Review Physics Education Research, Vol 13, No 020101 (2017)

[14] Ogilvie, C.A.: Changes in Students Problem Solving strategies in a Course That Includes Context -Rich, Multifaceted Problems. Physics Review Special Topics- Physics Education Research, Vol 5, 020102 (2009)

[15] Singh, C.: Assessing student expertise in introductory physics with isomorphic problems. I. Performance on nonintuitive problem pair from introductory physics. Physics Review Physics Education Research, Vol 4, No 010104 (2008) 